\title{
Suppressor of cytokine signaling gene expression in human pancreatic islets: modulation by cytokines
}

\author{
Carmela Santangelo, Angela Scipioni ${ }^{1}$, Lorella Marselli ${ }^{2}$, Piero Marchetti ${ }^{2}$ and Francesco Dotta ${ }^{3}$ \\ National Center for Food Quality and Risk Assessment, Istituto Superiore di Sanita, Rome, Italy, ${ }^{1}$ Department of Clinical Sciences - Endocrinology, \\ University La Sapienza, Policlinico Umberto I, Viale del Policlinico 155, 00 161, Rome, Italy, ${ }^{2}$ Department of Endocrinology and Metabolism - Metabolic \\ Unit, University of Pisa, Via Paradisa 2, 56100 Cisanello-Pisa, Italy and ${ }^{3}$ Department of Internal Medicine, Endocrine and Metabolic Sciences and \\ Biochemistry, University of Siena, Viale Bracci 18, 53100 Siena, Italy
}

(Correspondence should be addressed to F Dotta; Email: fradotta@tin.it)

\begin{abstract}
Objective: Suppressor of cytokine signaling (SOCS) proteins negatively regulate signal transduction of several cytokines. Since cytokines participate in the pancreatic islet damage in type 1 diabetes, the aim of our study was to investigate the expression of SOCS-1, -2 and -3 in isolated human islets, in basal conditions and after exposure, in vitro, to a combination of interferon (IFN)- $\gamma$, interleukin (IL)- $1 \beta$ and tumor necrosis factor (TNF)- $\alpha$ cytokines and in control and in type 1 diabetic human pancreata, to establish (i) whether SOCS molecules are constitutively expressed in human pancreatic islets and (ii) whether their expression can be modulated in vitro by proinflammatory cytokines or ex vivo by an islet inflammatory process.

Methods: Gene expression of SOCS-1, -2 and -3 was evaluated by RT-PCR in untreated and cytokinetreated isolated human pancreatic islets and their protein expression by immunohistochemistry in control and in type 1 diabetic human pancreata paraffin-embedded sections.

Results: We found that SOCS-1, -2 and -3 mRNA is constitutively, although weakly, expressed in human pancreatic islets, similar to the expression observed in control pancreata by immunohistochemistry. SOCS-1, -2 and -3 mRNA expression was strongly increased in human islets after exposure, in vitro, to IFN- $\gamma$, IL- $1 \beta$ and TNF- $\alpha$. Accordingly, an intense and islet-specific immunohistochemical staining for all three SOCS was detected in pancreata from type 1 diabetic patients.

Conclusion: SOCS-1, -2 and -3 genes are constitutively expressed in human pancreatic islets; their expression increases after exposure to proinflammatory cytokines and during an autoimmune inflammatory process, raising the possibility that these molecules act as key regulators of cytokine signaling in pancreatic islets.
\end{abstract}

European Journal of Endocrinology 152 485-489

\section{Introduction}

Human type 1 diabetes is caused by the autoimmune destruction of insulin-producing $\beta$-cells mediated by infiltrating T-lymphocytes, macrophages and their cytokine products (1). Increasing evidence indicates that proinflammatory and Th1 cytokines such as interferon (IFN) $-\gamma$, interleukin (IL)-1 $\beta$ and tumor necrosis factor (TNF)- $\alpha$, which are produced at the site of T-cell activation, play an important role in the development of the disease, both in rodents and in humans $(2,3)$. In particular, it has been shown that IFN- $\gamma$ is an important mediator of $\beta$-cell death, both in vitro and in vivo, and is able to induce, in combination with IL-1 $\beta$, inducible nitric oxide (NO) synthase expression and $\beta$-cell apoptosis (4). Moreover, other reports showed deleterious effects of a combination of IL- $1 \beta$, IFN- $\gamma$ and TNF- $\alpha$ on mouse NIT-1 $\beta$-cells and on intact mouse islets characterized by insulin release inhibition, Fas expression upregulation and NO production (5).
Cytokine-induced signal transduction pathways must be tightly regulated to avoid the harmful consequences of excessive stimulation. The suppressor of cytokine signaling (SOCS) family represents one of the inhibitors that contributes to the negative regulation of cytokine signaling. Data so far obtained indicate that SOCS proteins represent an important intracellular mechanism that defines the time and duration of the cellular response to cytokine stimulation, although cytokine-induced SOCS gene expression varies according to the cell type, to the experimental conditions and to the tissue being examined (6).

The SOCS family comprises at least eight members, SOCS-1 to SOCS-7 and cytokine-inducible SH2-containing protein, which share a central SH2 domain and a C-terminal SOCS box $(6,7)$. Cytokines activate several intracellular signaling pathways in order to exert their physiological effects. Receptors for several pro- and anti-inflammatory cytokines bind to members of the Janus kinase (JAK) family of tyrosine kinases and 
activate downstream signaling molecules known as signal transducers and activators of transcriptions (STATs). Since SOCS genes are induced by cytokines and the corresponding SOCS proteins inhibit cytokineinduced signaling pathways, SOCS proteins are believed to form part of a classic negative feedback loop; therefore, cytokine activation of the JAK-STAT pathway leads to the induction of SOCS genes. SOCS proteins appear to inhibit signaling by different mechanisms: by association with JAKs and inhibition of their catalytic activity, by binding to activated cytokine receptor and by blocking the access of phosphorylated STAT to the cytokine receptor (8).

Although IFN- $\gamma$ can induce the expression of SOCS-1, -2 and -3 mRNAs (7), SOCS-1 molecule is of particular importance in regulating the effects of $\operatorname{IFN}-\gamma$ (9), since its overexpression inhibits IFN- $\gamma$ signaling in several cell lines (10), including NIT-1 $\beta$-cells and mouse islets (11).

SOCS-2 appears to play an important role in regulating both growth hormone $(\mathrm{GH})$ and insulin-like growth factor (IGF)-I signaling (6); however, its overexpression can be induced also by proinflammatory cytokines such as IL-1 $\beta$ in human tonsillar cells and IFN- $\gamma$ in human bone marrow cells and granulocytes (12). SOCS-2 gene is expressed in non-obese diabetic severe combined immunodeficient (NOD-SCID) pancreatic islets and in NIT-1 insulinoma cells and up-regulated by IFN- $\gamma$, IL$1 \beta$ and TNF- $\alpha$ (10).

Studies in mouse bone marrow cells showed that SOCS- 3 was up-regulated by IL- $1 \beta$ and TNF- $\alpha$ (7). Moreover, overexpression of SOCS-3 has a protective effect in the rat $\beta$-cell line INS-1 exposed to IL-1 $\beta$ and/or IFN- $\gamma$ (13).

To date a few reports have been published $(10,11$, 13) on SOCS genes expression in rodent pancreatic islets, showing that SOCS overexpression could be a useful strategy to protect $\beta$-cell from the deleterious effect of proinflammatory cytokines. At the present time, no data are available about SOCS expression in human pancreatic islets.

In the present study we investigated, at the mRNA level the expression of SOCS-1, -2 and -3 in isolated human islets, in basal conditions and after exposure, in vitro, to a combination of IFN- $\gamma$, IL- $1 \beta$ and TNF- $\alpha$ cytokines, and at the protein level, by immunohistochemistry, in control and type 1 diabetic human pancreata, in order to establish (i) whether SOCS molecules are constitutively expressed in human pancreatic islets and (ii) whether their expression can be modulated in vitro by proinflammatory cytokine or $e x$ vivo by an islet autoimmune inflammatory process.

\section{Materials and methods}

\section{Isolation and culture of human islets}

In the present study we used vital purified human pancreatic islets obtained from three cadaveric multiorgan donors and prepared as previously described (14).
Within 7-10 days from isolation, aliquots of approximately 300 hand-picked islets were cultured free-floating for $10 \mathrm{~h}$ in Petri dishes containing $6 \mathrm{ml}$ supplemented Medium 199 (M199) culture medium under the following condition: (i) control M199; (ii) M199 containing 50 $\mathrm{U} / \mathrm{ml} \mathrm{IL}-1 \beta+1000 \mathrm{U} / \mathrm{ml}$ TNF- $\alpha+1000 \mathrm{U} / \mathrm{ml} \mathrm{IFN}-\gamma$. All cytokines were of human recombinant origin (Roche Diagnostics).

\section{RT-PCR analysis of SOCS mRNAs}

The expression of SOCS-1, -2 and -3 genes in human pancreatic islets, in all experimental conditions, was evaluated by RT-PCR. Total RNA was extracted from each sample with Trizol (Invitrogen) according to the manufacturer's instructions. Residual DNA was removed by treatment with DNAse-I (Invitrogen) for $15 \mathrm{~min}$ at room temperature. DNAse-I was inactivated by adding $25 \mathrm{mmol} / \mathrm{l}$ EDTA and heating for $10 \mathrm{~min}$ at $65^{\circ} \mathrm{C}$. First-strand cDNA synthesis was performed in a total volume of $20 \mu \mathrm{l}$, using $2 \mu \mathrm{g}$ of each RNA sample primed with random hexamers with 200 U Superscript II (Invitrogen); cDNA aliquots corresponding to $200 \mathrm{ng}$ RNA were subsequently amplified in a $100 \mu \mathrm{l}$ reaction volume containing $20 \mathrm{pmol}$ of sense and antisense specific primers and $2.5 \mathrm{U}$ Taq DNA polymerase (Invitrogen). The following primers were used: SOCS-1, sense $5^{\prime}-\mathrm{CAC}$ GCA CTT CCG CAC ATT C-3' and antisense 5'-AGC AGC TCG AGG AGG CAG TC-3' (297 bp product) (15); SOCS-2, sense 5'-AGA CAG GAT GGT ACT GGG GAA G-3' and antisense 5'-CTT GTT GGT AAA GGC AGT CCC-3' (446 bp product); SOCS-3, sense 5'-ACC TTC AGC TCC AAG AGC GAG TA-3' and antisense 5'-CGG AGT AGA TGT AAT ATG GCT CT-3' (439 bp product). The primers used for SOCS-2 and -3 amplification were constructed from the human cDNA sequences (SOCS-2 GeneBank: AF037989; SOCS-3 GeneBank: AF159854). Expression of $\beta$-actin as RNA control was analyzed employing the following primers, sense 5'-ACC AAC TGG GAG GAG ATG GAG-3' and antisense 5'-CGT GAG GAT CTT CAT GAG GTA AGT C-3' (354 bp product) (16).

cDNA was amplified in serial cycles ranging from 20 to 40 cycles in order to observe a linear amplification of PCR products. According to the results, after an initial denaturation step $\left(2 \mathrm{~min}\right.$ at $\left.95^{\circ} \mathrm{C}\right)$, $\beta$-actin was amplified by 25 cycles $\left(30 \mathrm{~s}\right.$ at $95^{\circ} \mathrm{C}, 30 \mathrm{~s}$ at $60^{\circ} \mathrm{C}$, $30 \mathrm{~s}$ at $72^{\circ} \mathrm{C}$ ) with $1.5 \mathrm{mmol} / \mathrm{l} \mathrm{MgCl}_{2}$ and SOCS-1, -2 and -3 by 35 cycles $\left(30 \mathrm{~s}\right.$ at $95^{\circ} \mathrm{C}, 30 \mathrm{~s}$ at $60^{\circ} \mathrm{C}, 30 \mathrm{~s}$ at $72{ }^{\circ} \mathrm{C}$ ) with $1.5,2.5$ and $1.5 \mathrm{mmol} / \mathrm{l} \mathrm{MgCl}_{2}$ respectively. The final extension period was $3.5 \mathrm{~min}$ at $72{ }^{\circ} \mathrm{C}$. Reaction conditions were standardized in order to observe a linear amplification of PCR products. All PCR products were electrophoresed on $1.2 \%$ ultrapure agarose 'Separide' (Invitrogen) and the bands visualized by ethidium' bromide staining. 
Semiquantitative analysis was performed by densitometric gel scanning utilizing a Bio-Rad 'Gel Doc 2000' video image system and results have been expressed as SOCS- 1 , -2 or $-3 / \beta$-actin density $\%$ ratio in each sample analyzed.

\section{Immunohistochemistry}

Human pancreatic paraffin sections were obtained from ten healthy (four females and six males, aged 14-45 years with no family history of type 1 or type 2 diabetes) and three type 1 diabetic organ donors (a 19-year-old male and a 14-year-old female who accidentally died 9 and 8 months after diabetes onset respectively, and a new-onset 5-year-old boy who died due to severe brain edema developing after diabetic ketoacidosis). Sections were dewaxed, treated with $0.3 \%$ hydrogen peroxidase in methanol for $30 \mathrm{~min}$ to quench endogenous peroxidase activity then processed in a microwave oven in $10 \mathrm{mmol} / \mathrm{l}$ citrate buffer $\mathrm{pH} 6$ followed by cooling at room temperature and finally incubated for $1 \mathrm{~h}$ at room temperature with purified goat polyclonal antibody to SOCS-1 (2 $\mu \mathrm{g} / \mathrm{ml}$; C-20; Santa Cruz Biotechnology Inc., Santa Cruz, CA, USA), rabbit polyclonal antibody to SOCS-2 (2 $\mu \mathrm{g} / \mathrm{ml}$; H-74; Santa Cruz Biotechnology) and rabbit polyclonal antibody to SOCS $-3(2 \mu \mathrm{g} / \mathrm{ml}$; H-103; Santa Cruz Biotechnology). Immunoreactivity was revealed using the streptavidin-biotin-peroxidase system and diamino-benzidine chromogen (LSAB + Kit, HRP; DAKO Corporation). Sections were counterstained with Mayer's hematoxylin. In order to assess specificity of the immunohistochemical staining, experiments in the absence of primary antibodies were performed as well.

\section{Results}

\section{Expression of SOCS mRNA in cultured human islets before and after cytokine treatment}

The presence of SOCS mRNA was analyzed by RT-PCR in healthy isolated human pancreatic islets in the resting condition and after $10 \mathrm{~h}$ in vitro treatment with a combination of IFN- $\gamma+$ IL- $1 \beta+$ TNF- $\alpha$. Low levels of SOCS-1, -2 and -3 mRNA were found to be constitutively expressed in untreated isolated human islets (Fig. 1A, lane A). We then investigated in human islets SOCS gene expression after $10 \mathrm{~h}$ incubation in vitro, with a combination of IFN- $\gamma+\mathrm{IL}-1 \beta+\mathrm{TNF}-\alpha$. The expression of SOCS-1, -2 and -3 genes was markedly increased (Fig. 1A, lane B) by such a treatment. Semiquantitative analysis performed by densitometric gel scanning showed (Fig. 1B) a significant upregulation $(P<0.05$ for SOCS-1 and -3 and $P<0.01$ for SOCS-2 by Mann-Whitney test) of SOCS expression in cytokine-treated islets.
A

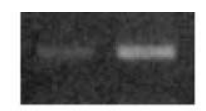

$300 \mathrm{bp}$

SOCS-2

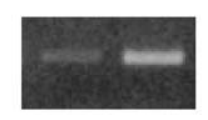

446bp

\section{SOCS-3}

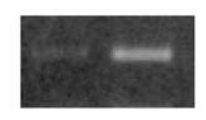
$\beta$-actin

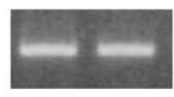

A B
SOCS-1
$439 \mathrm{bp}$

$542 b p$

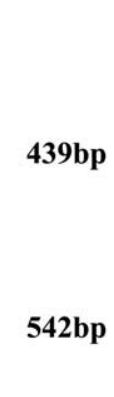

.

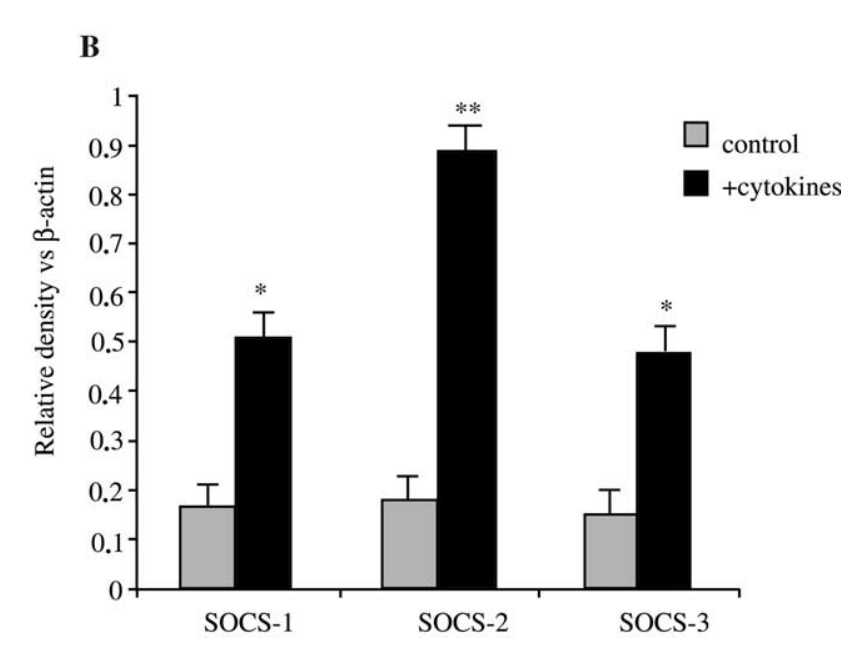

Figure 1 Expression of SOCS mRNA in cultured human islets before and after cytokine treatment. (A) RT-PCR for SOCS-1, -2 and -3 genes in human control islets (lane $A$ ) and human islets (lane B) exposed, in vitro, for $10 \mathrm{~h}$ to a combination of IFN $-\gamma$, IL-1 $\beta$ and TNF- $\alpha$ cytokines. (B) Data illustrated on the graph bar represent the means \pm S.D. of three different experiments. ${ }^{*} P<0.05,{ }^{*} P<0.01$ vs control.

\section{Expression of SOCS in human normal and type 1 diabetic pancreas:}

Immunohistochemical analysis of pancreatic sections from six control multiorgan donors, revealed that SOCS-1 was virtually undetectable and SOCS-3 were weakly expressed in pancreatic islet cells (Fig. 2A and E). SOCS-2 showed immunopositivity with only few cells with a cytoplasmic staining (Fig. 2 C). No specific staining for any of the SOCS molecules analyzed could be detected in exocrine pancreas.

All three type 1 diabetic pancreata analyzed showed an intense SOCS-1, -2 and -3 staining that could be 


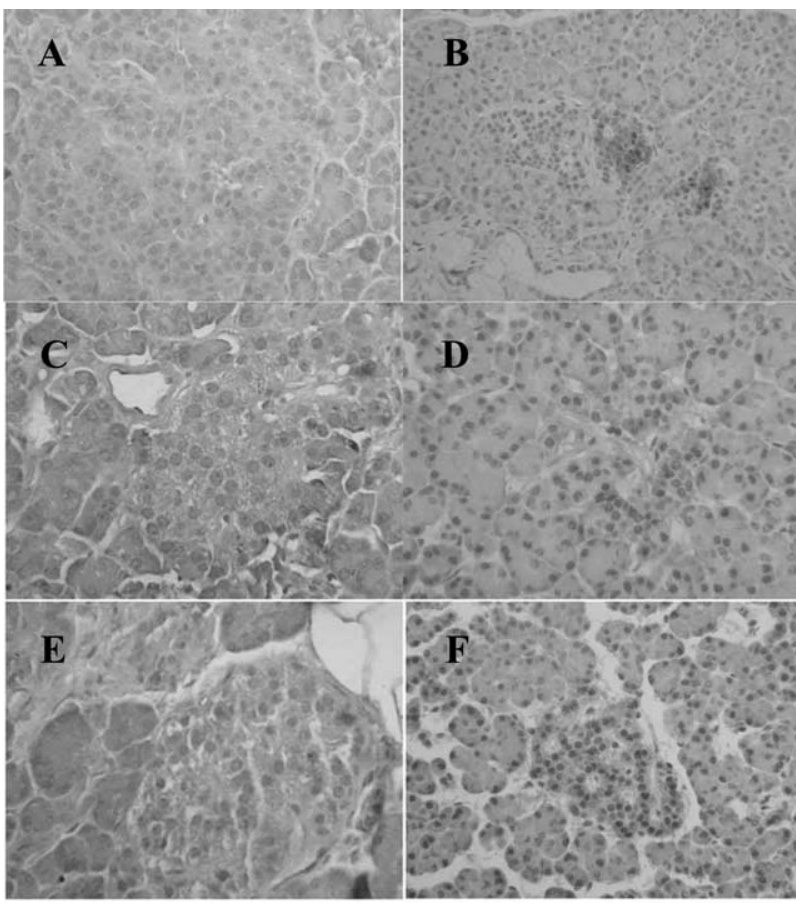

Figure 2 Expression of SOCS-1, -2 and -3 in human normal and type 1 diabetic pancreata. Immunohistochemistry for SOCS-1 $(A, B)$, SOCS-2 (C, D) and SOCS-3 (E, F) was performed on pancreatic paraffin sections from healthy $(A, C, E)$ and type 1 diabetic organ donors $(B, D, F)$. Magnification $\times 400(A, C-F)$ or $\times 250$ (B). A similar expression pattern was observed in all subjects analyzed.

detected in most pancreatic islets. As shown in Fig. 2, SOCS-1 (Fig. 2B), SOCS-2 (Fig. 2D) and SOCS-3 (Fig. 2F) were markedly expressed in the cytoplasm of a portion of islet cells. Single scattered acinar cells expressing SOCS-1 (Fig. 2B) or SOCS-3 (Fig. 2F) were also detected. The staining intensity and the number of islet cells expressing SOCS proteins did not appear to correlate with the intensity of the islet infiltration process. Control experiments in the absence of primary antibodies produced no staining (data not shown).

\section{Discussion}

In this study we show, for the first time, that SOCS-1, -2 and -3 genes are constitutively expressed in human pancreatic islets, and that their expression increases following exposure, in vitro, to a combination of proinflammatory cytokines such as IFN- $\gamma$, IL-1 $\beta$ and TNF- $\alpha$. Moreover, we have demonstrated that type 1 diabetic pancreata showed a strong islet-specific immunostaining for all three SOCS proteins tested, in contrast to control pancreatic islets, showing only a weak positivity. The differences between normal and type 1 diabetic pancreas are likely due to the mononuclear cell infiltrate as a possible source of proinflammatory cytokines.

SOCS-1 upregulation observed in human islets treated, in vitro, with IFN- $\gamma+\mathrm{IL}-1 \beta+\mathrm{TNF}-\alpha$ and in type 1 diabetic pancreata is in line with a number of reports showing that SOCS-1 is a key regulator and critical inhibitor of IFN- $\gamma$ signaling and is also able to suppress TNF- $\alpha$-induced cell death (17).

Taking into account that overexpression studies have pointed out that only the constitutive and continuous expression of SOCS-1 was able to inhibit cellular damage resulting from the combination of IFN- $\gamma$ and IL-1 $\beta(4,10)$, our data strengthen the regulatory role of SOCS-1, and that its overexpression could be an attempt to protect human $\beta$-cells from cytotoxic cytokines known to be important mediators in the progression of autoimmune diabetes (11).

The increase of SOCS-2 mRNA expression in cytokine-treated human islets associated with a strong immunopositivity of SOCS-2 protein in diabetic human islets provides evidence for an involvement of this molecule in the modulation of cytokine signaling during the insulitic process.

Although SOCS-2 overexpression is induced by proinflammatory cytokines in different human tissues (12), its regulatory role is less defined and perhaps more complex: SOCS-2 appears to play a primary role in regulating both $\mathrm{GH}$ and IGF-I signaling in humans and rodents (6) and in addition to SOCS-1 and -3 it is differentially regulated at the onset of labor thought to be initiated by inflammatory cytokines (18).

Moreover, results obtained from cotransfection studies showed that increasing concentrations of SOCS-2 inhibited, in a dose-dependent manner, the actions of SOCS-1 on cytokine signaling, suggesting that SOCS-2 at high concentrations might act to inhibit the function of other SOCS family members (19).

Our finding that exposure of human islets to inflammatory cytokines was associated with upregulation of SOCS-3, both in vitro and in vivo, is in line with studies indicating a role of this molecule in the modulation of IL-1 $\beta$ and TNF- $\alpha$ cytokine signaling (7). Furthermore SOCS-3 overexpression has a protective effect in the rat $\beta$-cell line INS-1 exposed to IL- $1 \beta$ and/or IFN- $\gamma$ (11) and it is able to drastically reduce the severity of arthritis in autoimmune rheumatoid arthritis (20).

Our data point to the existence of a complex crosstalk occurring among SOCS proteins and probably between SOCS and other proteins to regulate the action of different cytokines in diabetic human pancreatic islets.

The fact that SOCS-1, -2 and -3 expression is upregulated, in human islets, in response to cytokines both in vitro and more importantly during islet inflammation in vivo, strongly suggests a possible involvement of all these three SOCS in the modulation of cytokine action(s) in human pancreatic islets.

In conclusion, we have shown that human islet cells express a class of cytokine modulators such as SOCS proteins and that the expression of such molecules is increased by proinflammatory cytokines in vitro and during islet inflammation in type 1 diabetes. These 
findings suggest that modulation of SOCS expression, as suggested in animal models $(10,11,13)$, may represent a useful strategy to counteract the deleterious effects of proinflammatory cytokines in order to protect islet $\beta$-cells from immune-mediated destruction which takes place during type 1 diabetes development as well as during allograft rejection or recurrence of islet autoimmunity in type 1 diabetic patients transplanted with a whole pancreas or with purified islets.

\section{Acknowledgements}

This work was supported by grants from the Juvenile Diabetes Research Foundation, the Italian Ministry of Research, the Italian Ministry of Health and the Fondazione Promoter ONLUS.

\section{References}

1 Rabinovitch A. Update on cytokines in the pathogenesis of insulin-dependent diabetes mellitus. Diabetes and Metabolism Reviews 199814 129-151.

2 Stassi G, Maria RD, Rudert W, Testi R, Galluzzo A, Giordano C \& Trucco M. Nitric oxide primes pancreatic $\beta$-cells for Fas-mediated destruction in insulin-dependent diabetes mellitus. Journal of Experimental Medicine $1997 \mathbf{1 8 6} 1193-1200$.

3 Delaney CA, Pavlovich D, Hoorens A, Pipeleers DG \& Eizirik DL. Cytokines induce deoxyribonucleic acid strand breaks and apoptosis in human pancreatic islet cells. Endocrinology $1997 \mathbf{1 3 8}$ 2610-2614.

4 Cottet S, Dupraz P, Hamburger F, Dolci W, Jaquet M \& Thorens B. SOCS-1 protein prevents Janus kinase/STAT-dependent inhibition of $\beta$-cell insulin gene transcription and secretion in response to interferon- $\gamma$. Journal of Biological Chemistry $2001 \quad 276$ 25862-25870.

5 Zumsteg U, Frigerio S \& Hollander GA. Nitric oxide production and Fas surface expression mediate two independent pathways of cytokine-induced murine beta-cell damage. Diabetes $2000 \mathbf{4 9}$ $39-47$.

6 Krebs LD \& Hilton DJ. SOCS proteins: negative regulators of cytokine signaling. Stem Cells $200119378-387$.

7 Starr R, Wilson TA, Viney EM, Murray LJ, Rayner JR, Jenkins BJ, Gonda TJ, Alexander WS, Metcalf D, Nicola NA \& Hilton D. A family of cytokine-inducible inhibitors of signaling. Nature 1997 $387917-921$.

8 O'Shea J, Gadina M \& Screiber RD. Cytokine signaling in new surprises in the Jak/Stat pathway. Cell 2002109 S121-S131.

9 O'Shea JJ, Ma A \& Lipsky P. Cytokines and autoimmunity. Nature Reviews in Immunology 20022 37-45.

10 Chong MW, Thomas HE \& Kay TW. $\gamma$-Interferon signaling in pancreatic $\beta$-cells is persistent but can be terminated by overexpression of suppressor of cytokine signaling-1. Diabetes $2001502744-2751$

11 Chong MW, Thomas HE \& Kay TW. Suppressor of cytokine signaling-1 regulates the sensitivity of pancreatic $\beta$-cells to tumour necrosis factor. Journal of Biological Chemistry 2002 $27727945-27952$.

12 Dogusan Z, Hooghe-Peters EL, Berus D, Velkeniers B \& Hooghe R. Expression of SOCS genes in normal and leukemic human leukocytes stimulated by prolactin, growth hormone and cytokines. Journal of Neuroimmunology 2000109 34-39.

13 Karlsen AE, Ronn SG, Lindberg K, Johannesen J, Galsegaard ED, Pociot F, Nielsen JH, Mandrup-Poulsen T, Nerup J \& Billestrup N. Suppressor of cytokine signaling 3 (SOCS-3) protects $\beta$-cells against interleukin-1 $\beta$ - and interferon- $\gamma$-mediated toxicity. PNAS 200198 12191-12196.

14 Marchetti P, Dotta F, Ling Z, Lupi R, Del Guerra S, Santangelo C, Realacci M, Marselli L, Di Mario U \& Navalesi R. Function of pancreatic islets isolated from a type 1 diabetic patient. Diabetes Care $200023701-703$.

15 Schuringa JJ, Wierenga AT, Kruijer W \& Vellenga E. Constitutive Stat3, Tyr705, and Ser727 phosphorylation in acute myeloid leukemia cells caused by the autocrine secretion of interleukin-6. Blood $2000953765-3770$.

16 Marselli L, Dotta F, Piro S, Santangelo C, Masini M, Lupi R, Realacci M, del Guerra S, Mosca F, Boggi U, Purrello F, Navalesi R \& Marchetti P. Th2 cytokines have a partial, direct protective effect on the function and survival of isolated human islets exposed to combined proinflammatory and Th1 cytokines. Journal of Clinical Endocrinology and Metabolism $2001 \mathbf{8 6}$ 4974-4978.

17 Morita Y, Naka T, Kawazoe Y, Fujimoto M, Narazaki M, Nakagawa R, Fukuyama H, Nagata S \& Kishimoto T. Signals transducers and activators of transcription (STAT)-induced STAT inhibitor-1 (SSI-1)/suppressor of cytokine signaling-1 (SOCS-1) suppresses tumor necrosis factor alpha-induced cell death in fibroblasts. PNAS 200097 5405-5410.

18 Blumenstein M, Bowen-Shauver JM, Keelan JA \& Mitchell MD. Identification of suppressor of cytokine signaling (SOCS) proteins in human gestational tissues: differential regulation is associated with the onset of labor. Journal of Clinical Endocrinology and Metabolism 200287 1094-1097.

19 Favre H, Benhamou A, Finitori J, Kelly PA \& Edery M. Dual effects of suppressor of cytokine signaling (SOCS-2) on growth hormone signal transduction. FEBS Letters $1999 \mathbf{4 5 3} 63-66$.

20 Shouda T, Yoshida T, Hanada T, Wakioka T, Oishi M, Miyoshi K, Komiya S, Kosai K, Hanakawa Y, Hashimoto K, Nagata K \& Yoshimura A. Induction of the cytokine signal regulator SOCS3/CIS3 as a therapeutic strategy for treating inflammatory arthritis. Journal of Clinical Investigation $2001 \mathbf{1 0 8}$ $1781-1788$.

Received 9 August 2004

Accepted 22 November 2004 